\title{
Establishment Somatic Embryogenesis of Some Mango Rootstocks in Vitro
}

\author{
Hamdy, A. E. and Abdel-Aziz. H.F \\ Department of Horticulture, Faculty of Agriculture, Al-Azhar University, Nasr city, Cairo, Egypt. \\ Corresponding author: hosny_fathy86@azhar.edu.eg
}

\begin{abstract}
This work was an attempt to develop an In vitro technique for accomplished somatic embryos of some polyembryonic mango rootstocks (Saber and 13-1). Standardize in-vitro regeneration protocol in producing disease free; true-to-type and homogeneous high quality plants are prerequisite. Nucellar tissues from immature mango fruits of poly-embryonic rootstocks. The two mango rootstocks were cultured on full strength of B5 and MS media supplemented with different concentrations of some amino acids and vitamins. Embryos of (Saber and 13-1were used as a source of immature embryos (after pollination and fertilization stages) as explants. All 15 of day-old immature embryos of Sabre and 13-1 mango rootstocks were died after two months, while all other embryo ages 20,30, 40, 50 and 60 day-old were growth after the same time, also the best germination percentage, when immature embryos were cultured on the same media after 40 and 50 days from pollination and fertilization stages. MS media supplemented with $2.0 \mathrm{mg} / \mathrm{L}$ of BA possessed the highest embryos number per germinated embryo compared with another rootstock on the same media. The highest germinated embryos achieved when somatic embryogenesis of tow mango rootstocks were cultured on half - strength MS media were supplemented with 30\% sucrose compared with other treatments. Half-strength MS was superior to full-strength MS media on germination stage. Saber mango rootstock was superior to 13-1 rootstock regarding to the direct somatic embryogenesis; development of embryos; large scale somatic embryogenesis and the highest germination percentage and number of germinated embryos; on the other hand, Saber mango rootstock was least mango rootstock regarding the highest death percentage of embryos compared with 13-1 mango rootstock. It could be recommended that somatic embryogenesis technique possibility of a rapid multiplication on the mango rootstocks saber and 13-1 grew into plantlets.
\end{abstract}

Keywords: Saber; 13-1; B5; MS; immature embryos, Nucellar, embryo culture, germination

\section{Introduction}

Mango (Mangifera indica L.) belongs to the dicotyledonous family Anacardiaceae (Cany et al., 1981). According to the latest statistics provided by the Ministry of Agriculture (2017) indicated that, a total of 240804 Faddan are planted by mangoes. Somatic embryogenesis has been reported in several mango cultivars (most of which are polyembryonic ((Shaban, 2010 and Nower, 2013). Although review of literature on mango somatic embryogenesis abounds (recently reviewed by Krishna and Singh, 2007; Litz et al., 2009). Polyembryonic seeds contain many embryos, most of which are asexual (nucellar) in origin and genetically identical to the maternal parent. Polyembryonic seeds also contain a zygotic embryo that is the result of cross-pollination (Bally, 2009). Also, in polyembryonic seeds not all zygotic seedlings were produced by small embryos located at the micropyle (Ochoa et al., 2012). Probable reasons are the generalized recalcitrance of mango tissues derived from adult plants to in vitro procedures, in which the chief obstacles are the inherently slow in vitro response and phenolic oxidation giving rise to media browning and, more importantly, explant necrosis (Krishna et al., 2008). Somatic embryogenesis in mango is one of the micropropagation techniques which depend on induction of nucellar tissue in ovular halves of fruits to produce callus, somatic embryo formation, proliferation of somatic embryos and their synchronized development into plantlets (Chaturvedi et al., 2004). The induction of embryogenic cultures in mango is primarily dependent upon the morphogenetic potential of the nucleus, a maternal tissue that encompasses the embryo sac. In polyembryonic genotypes, adventitious embryos differentiate from competent cells, which are present within the nucleus (Litz and Gómez-Lim 2005) With regard to sucrose content; different concentrations have been used for the maturation of mango somatic embryos. Mango suffers from heavy fruit drop and hence embryo culture can improve breeding efforts (Iyer and Subramanyam, 1971). Several factors associated with fruit drop include competition among developing fruitlets, deficient nutrition, moisture stress, hormone imbalance, climatological factors like high temperature, rains during flowering, high wind velocity, varietal factor, lack of fertilization and attack of diseases and pests (Sawke et al., 1990). Smith $\boldsymbol{e t}$ al., (2008) reported that Sabre stock was originally at South Africa while (13-1) at Egypt. Gazit and Knight, (1989) stated that (13-1) was found to be selfincompatible in pollination studies Polyembryonic rootstock (13-1) has been demonstrated to tolerate calcareous soil containing $20 \%$ calcium carbonate and saline irrigation water containing $>600$ ppm chloride. Gazit and Kadman (1980) grew 'Maya' on '13-1' rootstock on calcareous soils with up to $20 \%$ lime and 250 ppm chloride. Shaban, (2010) found that Sabre rootstock could be considered as a semi dwarfing stock and 13-1 a dwarfing rootstock. On the other 
hand, seed germination percentage at vivo of mango rootstocks was 43 and $58 \%$ for the two rootstocks (Saber and 13-1) respectively. Therefore, the aim of this study is establish a protocol for in vitro plant recovery through embryo culture and test its performance on somatic and zygotic embryos from well-known mango rootstocks (Saber and 13-1) during maturation under different culture systems and growth media.

\section{Materials and Methods}

This study was carried out during the period from 2018 to 2019 in the Laboratory of Tissue Culture, Department of Horticulture Faculty of Agriculture, Al-Azhar University, Cairo, Egypt.

\section{Plant material}

Forty fruits of five developmental stages were collected, after 15, 20, 30, 40, 50 and 60 days according to (Nower, 2013) after fruit set, from a tree of (Sabre and 13/1 from south Africa) ) mango rootstocks of this study were obtained from a privet orchard in Wadi El- molak Ismailia Governorate.

\section{Explants and surface sterilization:}

Mango fruits were surface-sterilized by soaking in $10 \%$ commercial bleach (containing $5.5 \%$ sodium hypochlorite ) for $20 \mathrm{~min}$, followed by three rinses with double sterile distilled water. Fruits were then dipped in $95 \%$ ethanol and flamed for a few seconds (Xiao et al., 2004). The embryos were discarded from each ovule and the intact ovular halves containing nucellar tissue were placed in a nutrient medium .

\subsection{Effect of developmental stage of embryos on responses embryos of tow mango rootstocks growing in vitro:}

This experiment was carried out to study the effect of day-old of fruits age after pollination or fertilization stage of formation somatic embryogenesis of two mango rootstocks such as saber and 13-1. All ages embryos of two mango rootstocks were cultured on full strength B5 or MS media supplemented with Lglutamine $400 \mathrm{mg} / \mathrm{L}$; Myo-inositol $100 \mathrm{mg} / \mathrm{L}$; Thiamine $\mathrm{HCl} 1.0 \mathrm{mg} / \mathrm{L}$; ascorbic acid $150 \mathrm{mg} / \mathrm{L}$; citric acid $100 \mathrm{mg} / \mathrm{L}$; sucrose $6 \%$ (w/v); $1.5 \mathrm{~g} / \mathrm{L}$ active charcoal; 2, 4, D at $0.5 \mathrm{mg} / \mathrm{L}$ and $7 \mathrm{~g} / \mathrm{L}(\mathrm{w} / \mathrm{v})$. The incubation was done in a growth chamber at $27 \pm 2{ }^{\circ} \mathrm{C}$ and exposed to the darkness for eight weeks .The recultures were conducted at each 21 days. These cultures were used as a mother stock for the subsequent proliferation experiments. The incubation was done in a growth chamber at $27 \pm 2{ }^{\circ} \mathrm{C}$ and exposed to a $16 \mathrm{~h} /$ day and $8 \mathrm{~h} /$ day darkness, photoperiod at an intensity of 1500 lux from cool white fluorescent lamps. The $\mathrm{pH}$ of media was adjusted at 5.7 by adding a few drops of either potassium hydroxide $(\mathrm{KOH})$ at $0.1 \mathrm{~N}$ or hydrochloric acid (HCL) at $0.1 \mathrm{~N}$. Twenty five $\mathrm{ml}$ of media were dispensed into $100 \mathrm{ml}$ glass jars. Transparent polypropylene lids were used for covering the culture jars. Then the media were sterilized by autoclaving the jars under pressure of 1.5 $\mathrm{Kg} / \mathrm{cm}^{2}$ and at $121{ }^{\circ} \mathrm{C}$ for 20 minutes. The jars were transferred to the culture cabinet and left to cool in a slant position till they were used.

\subsection{Large scale somatic embryogenesis of tow mango rootstocks growing in vitro:}

This experiment was carried out to study the effect of full strength B5 media supplemented with $400 \mathrm{mg} / 1$ L-glutamine; Myo-inositol 100 (mg/ 1); $150 \mathrm{mg} / \mathrm{l}$ ascorbic acid; Thiamine $\mathrm{HCl} 1.0(\mathrm{mg} / \mathrm{l}) ; 100 \mathrm{mg} / \mathrm{l}$ citric acid; BA 0.0,0.5,1.0 and $2.0 \mathrm{mg} / \mathrm{L} ; 6 \%$ (w/v) sucrose; $1.5 \mathrm{~g} / \mathrm{L}$ active charcoal and $0.7 \%(\mathrm{w} / \mathrm{v})$ on mass production embryos number of two mango rootstocks. All cultured jars were incubated under conditions in a growth chamber at $27 \pm 2{ }^{\circ} \mathrm{C}$ and exposed to the darkness for eight weeks .The recultures were conducted at each 21 days. These cultures were used as a mother stock for the subsequent proliferation experiments.

\subsection{Germination somatic embryogenesis of tow mango rootstocks growing in vitro.}

This experiment was carried out to study the effect of full or half -strength MS media supplemented with $\mathrm{BA}$ at $0.5 \mathrm{mg} / \mathrm{L} ; \mathrm{GA}_{3}$ at $0.5 \mathrm{mg} / \mathrm{L}$; IBA at $1.0 \mathrm{mg}$ /L ; L-glutamine $400 \mathrm{mg} / \mathrm{L}$; Myo-inositol $100 \mathrm{mg} / \mathrm{L}$; ascorbic acid150 mg/L; Thiamine $\mathrm{HCl} 1.0 \mathrm{mg} / \mathrm{L}$; citric acid $100 \mathrm{mg} / \mathrm{L}$; active charcoal $1.5 \mathrm{~g} / \mathrm{L}$; agar 7 $\mathrm{g} / \mathrm{L}(\mathrm{w} / \mathrm{v})$ and different concentrations of sucrose 30 , 45 and $60 \mathrm{~g} / \mathrm{L}$ on germination percentage( $\%$ ) of two mango rootstocks after eight weeks.

Statistical Analysis: a complete randomized design was followed and analysis of variance (ANOVA) was performed using two ways ANOVA Co-stat software according to Stern (1991).

\section{Results and Discussion}

\subsection{Responses embryos to developmental stage of embryos of tow mango rootstocks growing in vitro:}

Data in figs from 1 up to 3 showed the effect of different ages of embryos $(15,20,30,40,50$ and $60-$ day-old after pollination and fertilization stages) on the number of embryos formed, embryos formation percentage and embryos death percentage of two mango rootstocks. The results showed that culturing the separate embryos of tow mango rootstocks from the fruits after 15-day from pollination and fertilization stage on both the MS and B5 medium were died after eight weeks. All other examined embryo ages 20, 30, 40, 50 and 60 day-old of mango rootstocks (Sabre and 13-1) showed a swelling (growth) after eight weeks achieved when cultured on both full strength MS and B5 medium supplemented 
with L-glutamine $400 \mathrm{mg} / \mathrm{L}$; Myo-inositol $100 \mathrm{mg} / \mathrm{L}$; Thiamine $\mathrm{HCl} 1.0 \mathrm{mg} / \mathrm{L}$; ascorbic acid $150 \mathrm{mg} / \mathrm{L}$; citric acid $100 \mathrm{mg} / \mathrm{L}$; sucrose $6 \%(\mathrm{w} / \mathrm{v}) ; 1.5 \mathrm{~g} / \mathrm{L}$ active charcoal; 2, 4, D at $0.5 \mathrm{mg} / \mathrm{L}$ and $7 \mathrm{~g} / \mathrm{L}(\mathrm{w} / \mathrm{v})$.

As for direct somatic embryogenesis growing in vitro observed in figs from 1 up to 3 showed that the direct somatic embryos were induced from ages 40 and 50-day-old of Sabre and 13-1 mango rootstocks. And also, it was clear that the ages 20 and 30 -day-old after pollination and fertilization stages of both examined rootstocks (Sabre and 13-1) showed the development in growth of the cultured embryos (explants) without formation of somatic embryogenesis. At the same time, culturing the embryos from 60-day-old fruits after pollination and fertilization stage on the previous full strength MS and B5 medium led to germination of some embryos and development in growth of the cultured embryos (explants) without formation of somatic embryogenesis compared with other ages. Gamborge's B5 media super than MS media in all previous morphological characteristics. These results are agreement with Ara et al., (2004) found that thirty to sixty-day-old fruits, harvested after pollination are suitable for induction of somatic embryogenic culture from the nucellus of some mango cultivars. In addition (Sulekha and Rajmohan, 2004) who found that forty to fifty-days-old fruits, harvested after fruit set time are suitable for induction of somatic embryogenic culture from the nucleus of mango. Also, Nower, (2013) who found that direct somatic embryogenesis were induced on embryos of age 45 ; 60 and 75 -day old of some mango cultivars growing in vitro compared with $15-$ day old after fruit set which were died. Also, Sahijram et al., (2005) suggested collection of mango fruitlets at 6-8 weeks postpollination for embryo culture. Hybrid embryos were aseptically excised from immature ovules and thereafter, inoculated in vitro onto semi-solid halfstrength modified MS medium containing casein hydrolysate $(1.25 \mathrm{~g} / \mathrm{L})$ and sucrose $(4.5 \%)$.

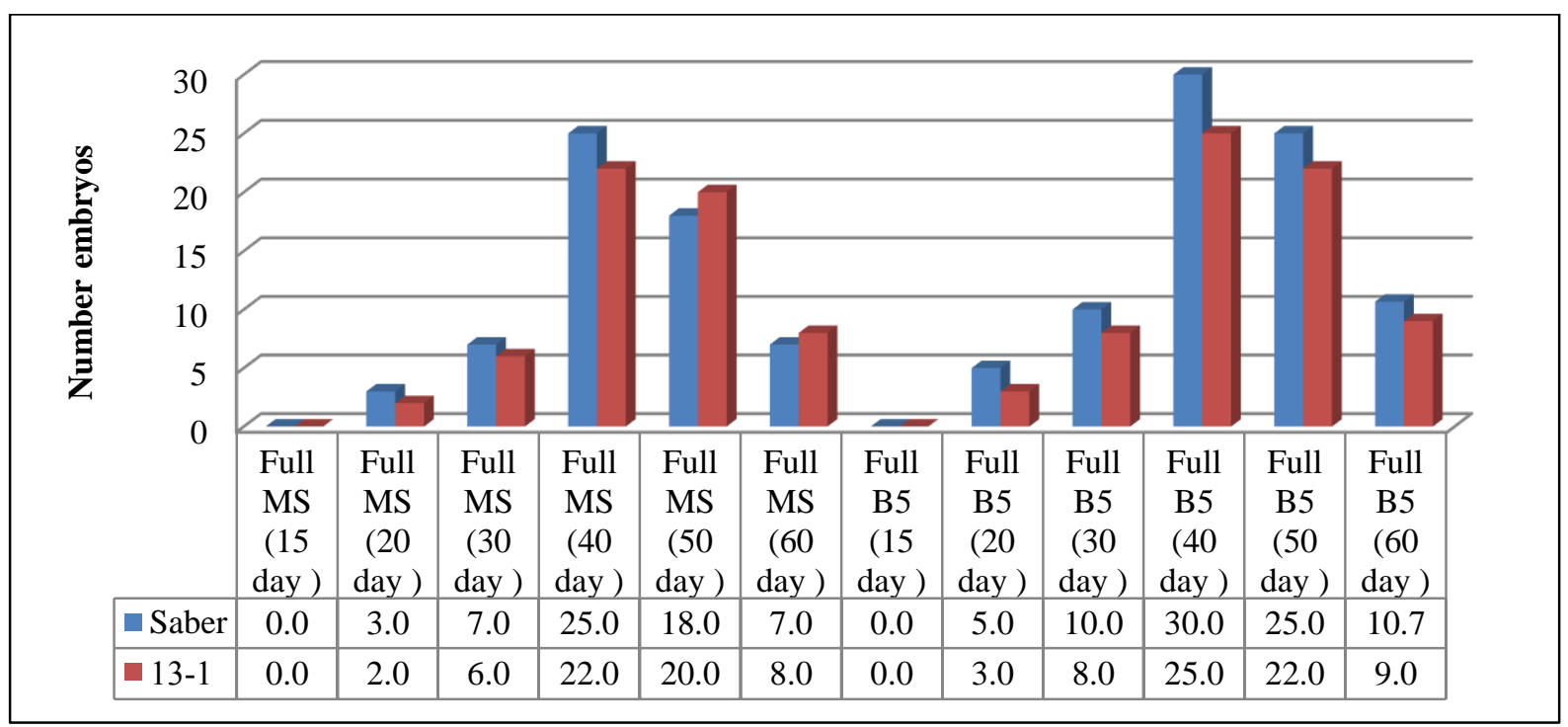

L.S.D at $5 \%$ of rootstocks $=1.24$, L.S.D at $5 \%$ of treatments $=3.04$, L.S.D at $5 \%$ of R X T $=4.3$

Fig.1. Effect of developmental stage of embryos on number embryos of tow mango rootstocks growing in vitro:

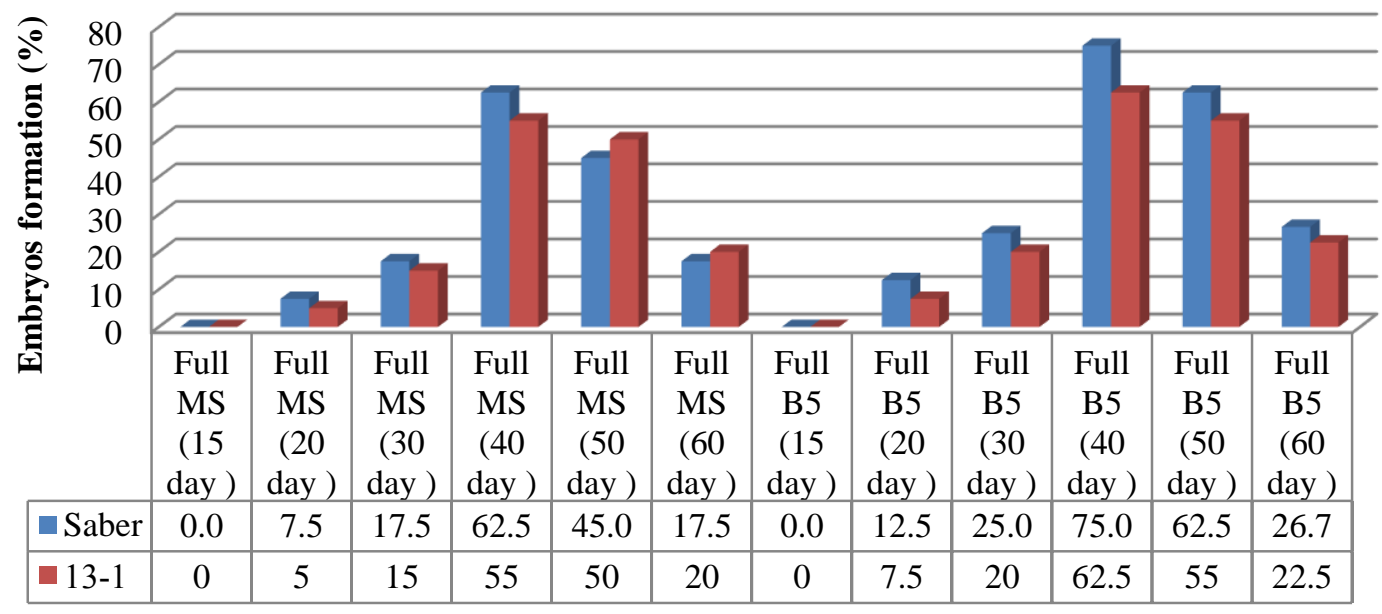

L.S.D at $5 \%$ of rootstocks $=3.10$, L.S.D at $5 \%$ of treatments $=7.61$, L.S.D at $5 \%$ of R X T $=10.77$ 
Fig.2. Effect of developmental stage of embryos on embryos formation percentage of tow mango rootstocks growing in vitro:

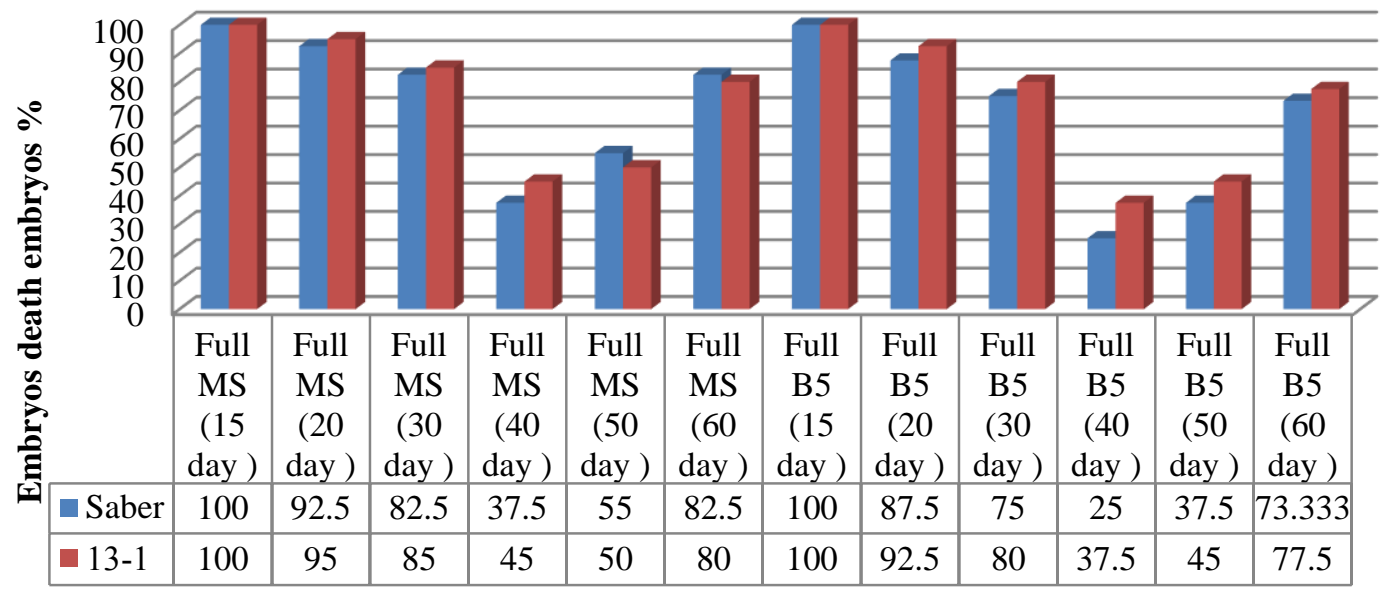

L.S.D at $5 \%$ of rootstocks $=3.10$, L.S.D at $5 \%$ of treatments $=7.61$, L.S.D at $5 \%$ of R X T $=10.77$

Fig.3. Effect of developmental stage of embryos on embryos death percentage of tow mango rootstocks growing in vitro:

\section{Large scale somatic embryo germination:}

Data in Figs. From 4 and 5 showed the effect of full- strength MS media supplemented with Lglutamine $400 \mathrm{mg} / \mathrm{L}$; Myo-inositol $100 \mathrm{mg} / \mathrm{L}$; Thiamine $\mathrm{HCl} 1.0 \mathrm{mg} / \mathrm{L}$; ascorbic acid $150 \mathrm{mg} / \mathrm{L}$; citric acid $100 \mathrm{mg} / \mathrm{L} ;$ sucrose $6 \%$ (w/v); $1.5 \mathrm{~g} / \mathrm{L}$ active charcoal; BA at $(0.0,0.5,1.0$ and $2.0 \mathrm{mg} / \mathrm{L})$ and $7 \mathrm{~g}$ $/ \mathrm{L}(\mathrm{w} / \mathrm{v})$ on mass production somatic embryogenesis of two mango rootstocks. The results showed that significant differences between the numbers of somatic embryos parameter of both two mango rootstocks. It was found that adding BA at $2.0 \mathrm{mg} / \mathrm{L}$ to the growth MS media caused an increase in embryos number / somatic embryogenesis and embryos fresh weight (g) / embryo compared with those of control and other treatments. Sabre rootstock was superior to 13-1 rootstock regarding the number of somatic embryos per embryo affected by different concentrations of BA. As a matter of fact the embryogenic response is strongly rootstocks dependent. On the basis of their embryogenic response, Litz and Lavi (1997) classified some varieties as highly embryogenic (polyembryonic Hindi and Parris), moderately embryogenic (monoembryonic Lippens and Tommy Atkins) and difficult-to-regenerate (polyembryonic Nam Doc Mai). They also demonstrated that nurse culture derived from Parris can improve the embryogenic response of non-embryogenic cultures. Litz and Yurgalevitch (1997) suggested that differential regulation of ethylene biosynthesis and the enzyme spermidine synthase in mango may be major contributing factors in controlling induction of somatic embryos in vitro and confirmed the effects of spermidine in induction of embryogenic competence in mango cultures. 


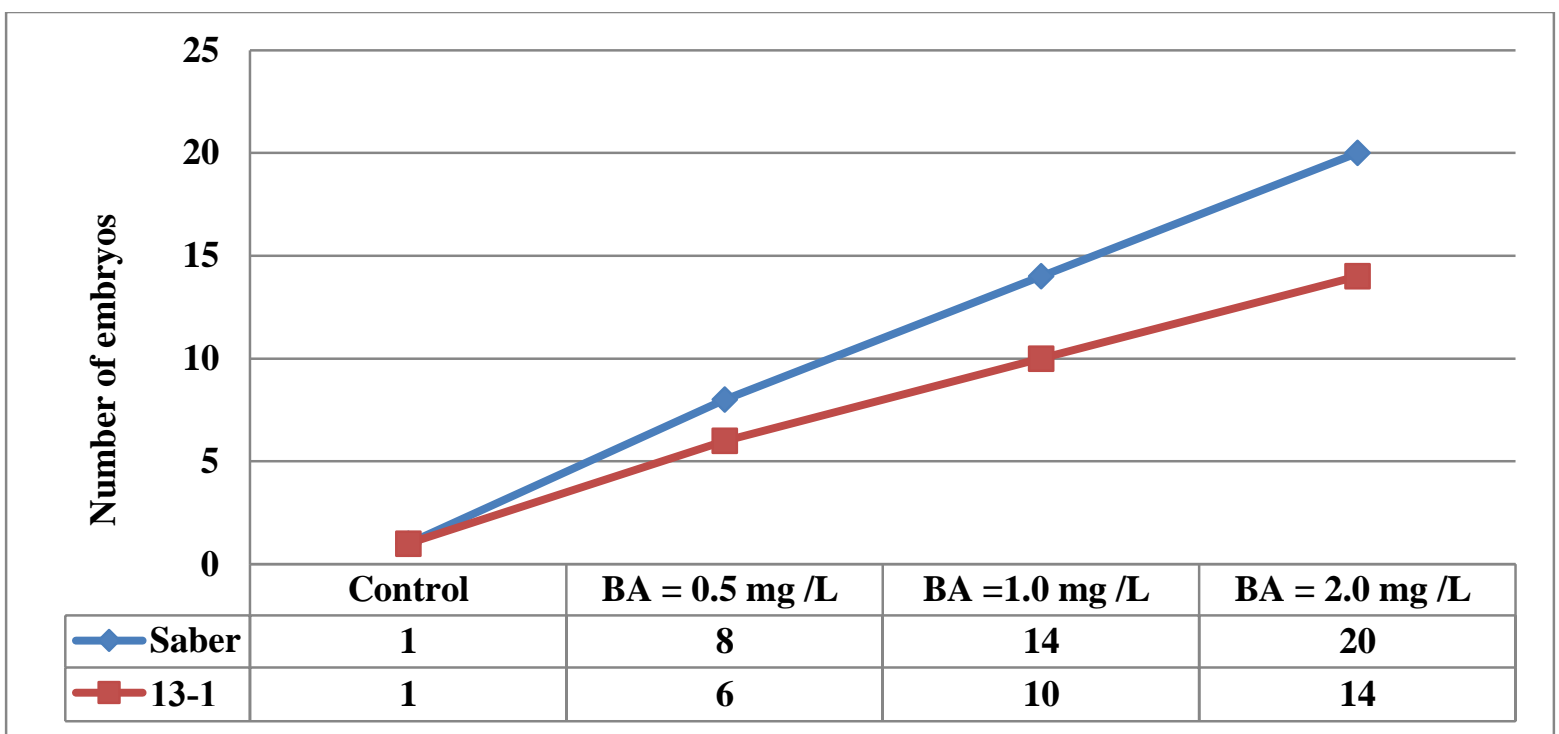

L.S.D at $5 \%$ of rootstocks $=0.16$, L.S.D at $5 \%$ of treatments $=0.22$, L.S.D at $5 \%$ of R X T $=0.32$

Fig.4.Effect of MS media supplemented with different concentrations of BA on embryos number of tow mango rootstocks growing in vitro:

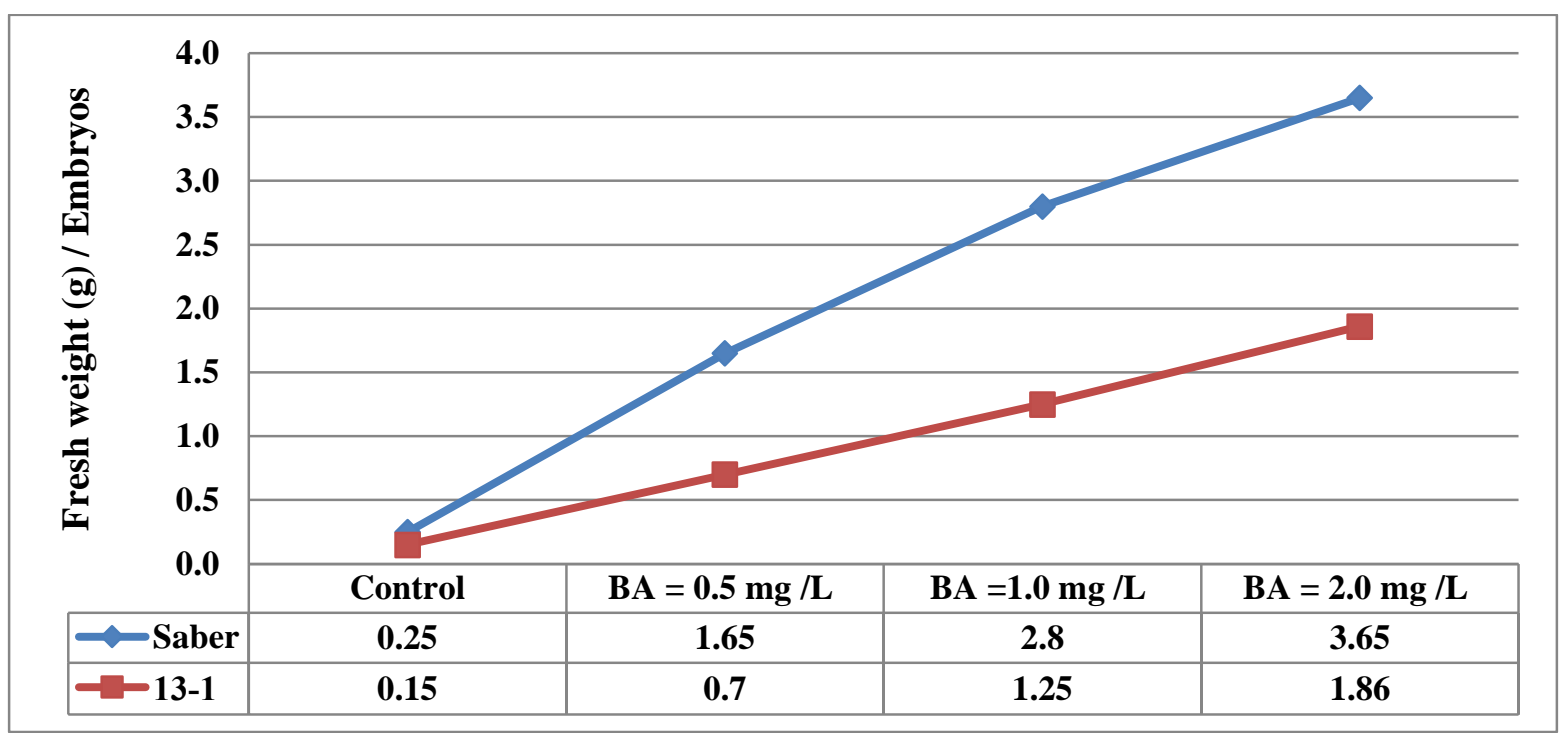

L.S.D at $5 \%$ of rootstocks $=0.16$, L.S.D at $5 \%$ of treatments $=0.22$, L.S.D at $5 \%$ of R X T $=0.32$

Fig.5.Effect of MS media supplemented with different concentrations of BA on fresh weight (g)/ embryos of tow mango rootstocks growing in vitro:

\subsection{Regenerated plantlet with shoots and roots.}

Data in Figs 6 and 7 showed the effect strength of MS media on germination percentage and number of germinated embryos. The results showed that culturing the somatic embryogenesis on full or half- strength MS media supplemented with BA at 0.5 $\mathrm{mg} / \mathrm{L} ; \mathrm{GA}_{3}$ at $0.5 \mathrm{mg} / \mathrm{L} ; \mathrm{IBA}$ at $1.0 \mathrm{mg} / \mathrm{L} ; \mathrm{L}-$ glutamine $400 \mathrm{mg} / \mathrm{L}$; Myo-inositol $100 \mathrm{mg} / \mathrm{L}$; ascorbic acid150 mg/L; Thiamine $\mathrm{HCl} 1.0 \mathrm{mg} / \mathrm{L}$; citric acid $100 \mathrm{mg} / \mathrm{L}$; active charcoal $1.5 \mathrm{~g} / \mathrm{L}$; agar 7 $\mathrm{g} / \mathrm{L}(\mathrm{w} / \mathrm{v})$ and different concentrations of sucrose 30 , 45 and $60 \mathrm{~g} / \mathrm{L}$ caused an increase in germination percentage of two mango rootstocks. The maximum germination percentage and the highest germinated number of two mango rootstocks achieved when embryos were cultured on half- strength MS media supplemented with $3 \%$ sucrose compared with other treatments. Half- strength MS media was superior on full-strength MS media supplemented with all concentrations of sucrose of tow tested mango rootstocks. MS media in half or full strength supplemented with 3\% sucrose caused the highest germination percentage and the highest germinated numbers of tow mango rootstocks in comparison with all concentrations of sucrose. Theses result are agreement with Pérez-Hernández and GrajalMartín (2011) reported that adding sucrose at 45 and $60 \mathrm{~g} / \mathrm{L}$ to MS media enhanced germination 'Lippens' 
and 'Keitt embryos of mango cultivars. Also, Laxmi et al., (1999) showed that lowering of sucrose concentration and addition of $\mathrm{GA}_{3}$ and N6benzylamino purine for improved somatic embryo germination. Germination was achieved on a medium with B5 major salts, MS minor salts and organics. The importance of sucrose and salts strength, in developing embryos of mango, was also reported by Litz and Gomez-Lim (2005) advocated reduction in concentration of sucrose in maturation medium from 6 to $4 \%$. The sucrose concentration is gradually reduced to $1.0 \%$ during sequential subculture to fresh medium owing to different requirements of developing embryos from heart stage to complete maturity stage. Recently, Xiao et al., (2004) reported direct somatic embryogenesis and plantlet regeneration from cotyledon of immature zygotic embryos. PEM-like structures were directly induced on modified MS medium with $25 \mu \mathrm{M}$ IBA. Later, conversion of somatic embryos was accomplished on a medium containing $23 \mu \mathrm{M}$ kinetin. Besides, secondary somatic embryogenesis could also be achieved on hypocotyls of mature primary somatic embryos cultured on the conversion medium.

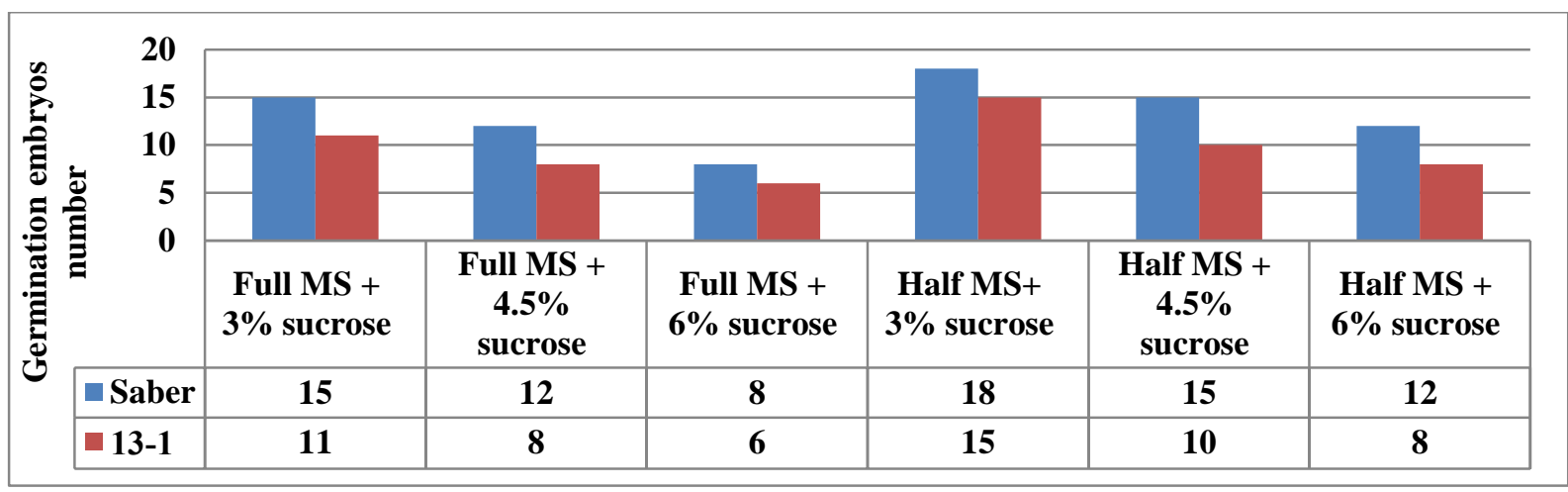

L.S.D at $5 \%$ of rootstocks $=1.1$, L.S.D at $5 \%$ of treatments $=2.06$, L.S.D at $5 \%$ of R X T $=2.9$

Fig.6. Effect of Strength MS media supplemented with different concentrations of sucrose on germination embryos number of tow mango rootstocks growing in vitro.

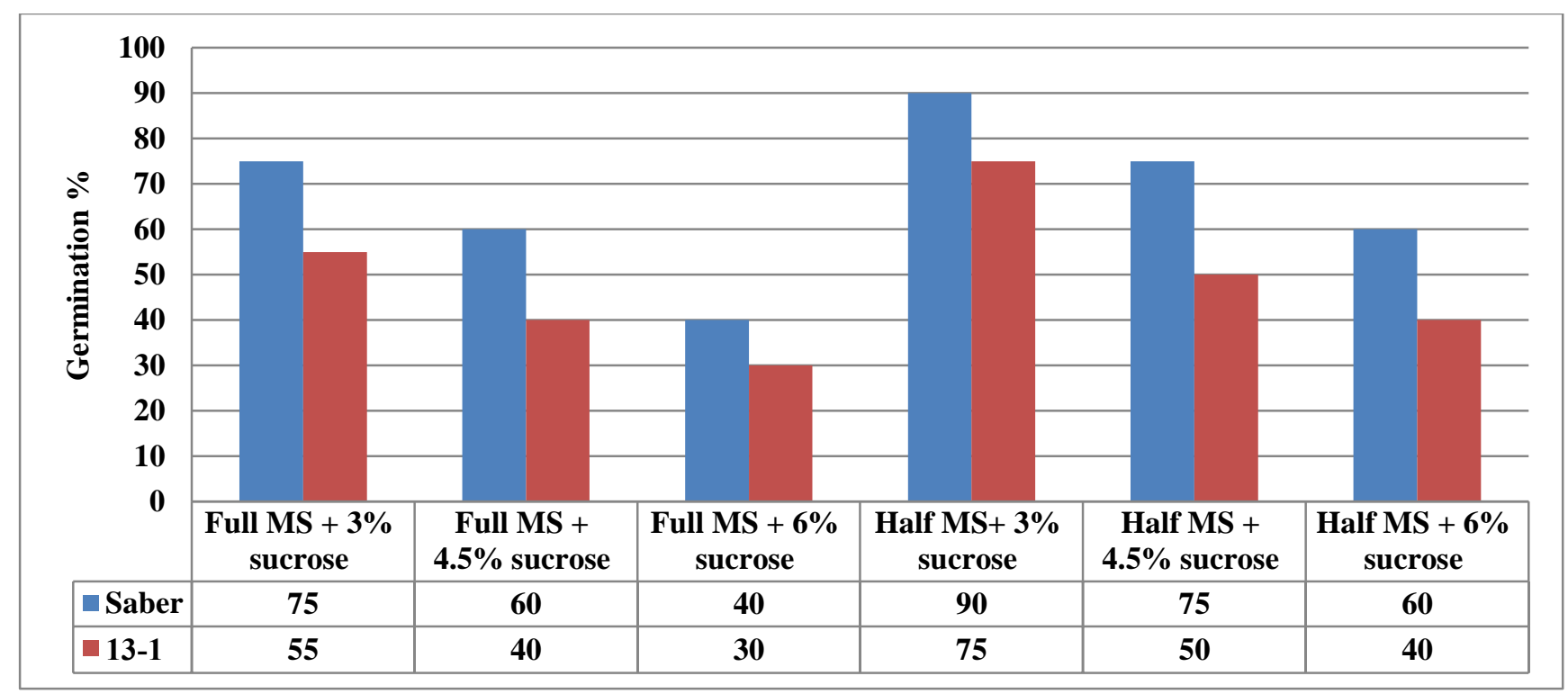

L.S.D at $5 \%$ of rootstocks $=5.9$, L.S.D at $5 \%$ of treatments $=10.3$, L.S.D at $5 \%$ of R X T $=14.5$

Fig.7. Effect of Strength MS media supplemented with different concentrations of sucrose on germination percentage of tow mango rootstocks growing in vitro 


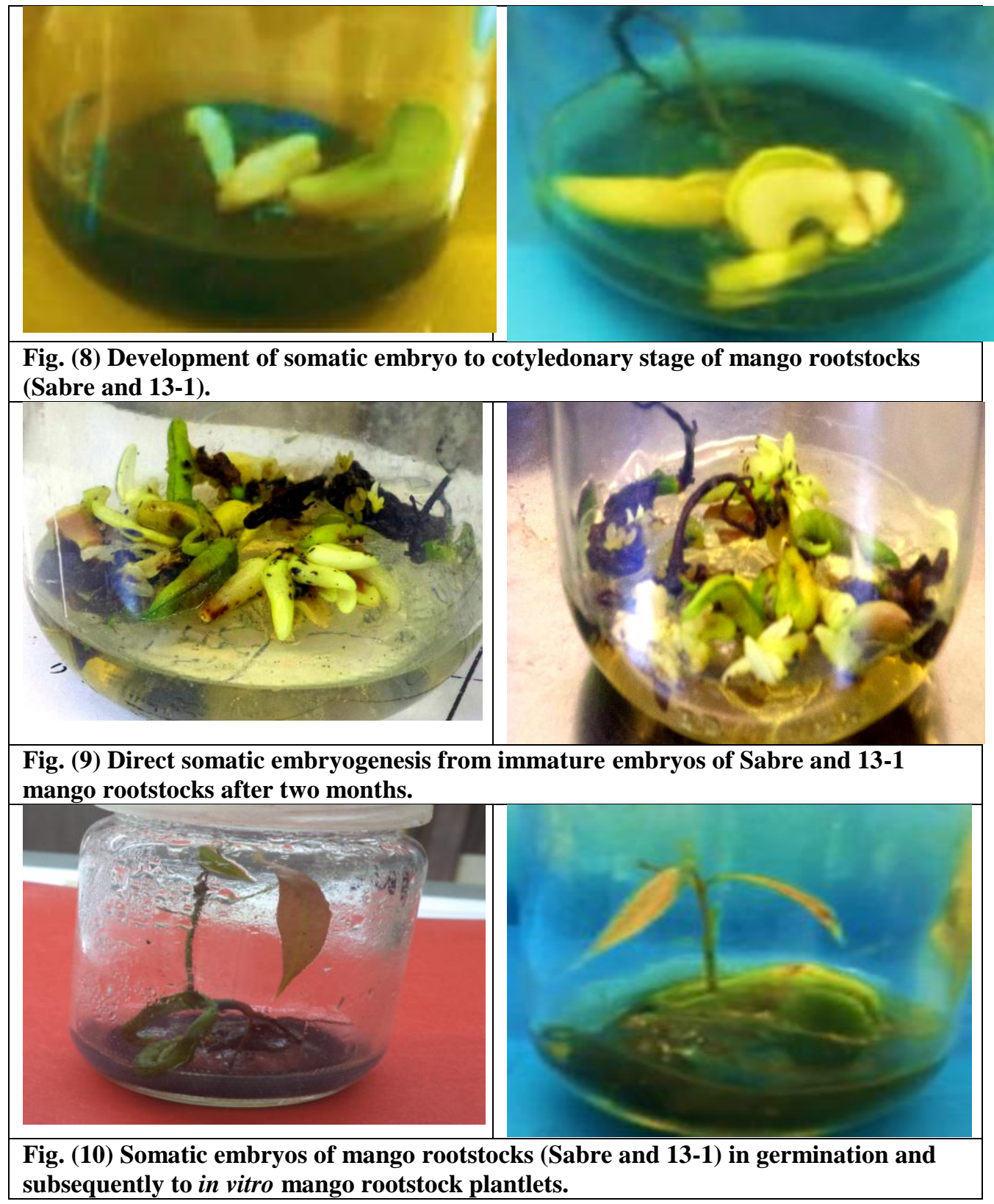

\section{Conclusion}

- $\quad$ MS media supplemented with $2.0 \mathrm{mg} / \mathrm{L}$ of BA possessed the highest embryos number per germinated embryo compared with another rootstock on the same media.

- The highest germinated embryos achieved when somatic embryogenesis of tow mango rootstocks were cultured on half - strength MS media were supplemented with $30 \%$ sucrose.

- It could be recommended that somatic embryogenesis technique possibility of a rapid multiplication on the mango rootstocks saber and 13-1 grew into plantlets.

\section{References}

Ara. H; Jaiswal. U and Jaiswal. V.S. (2004) An improved method of proliferation of proembryogenic calli of Mangifera indica L. var. Amrapali for scale-up of somatic embryo production. Indian J Biotechnol 2004;3:229-34.

Bally. I. S; Lu, P and Johnson. P. R (2009). Mango breeding. In Breeding plantation tree crops: tropical species (pp. 51-82). Springer, New York, NY.

Cany. Y, Zaini. S and Idris. A (1981) Genetic variation in the grafted vegetatively propagated Mango (Mangijera indica L).; Pertanika 4(1), 5362. 
Chaturvedi HC, Agnihotri S, Sharma M, Sharma AK, Jain M, Gupta P,

Gazit. S. and Knight R.J (1989). Asexual embryogenesis in the mango. BARD Project Rpt. I-255-80.

Kidwai NR (2004). Induced nucellar embryogenesis in vitro for clonal multiplication of Mangifera indica L. var. Ambalavi: A dwarfing rootstock. Indian J. Biotechnol. 3(2):221-228.

Krishna. H. and S.K. Singh. (2007). Biotechnological advances in mango (Mangifera indica L.) and their future implication in crop improvement-A review. Biotechnol. Adv. 25:223-243.

Krishna. H; Sairam. R. K; Singh. S. K; Patel. V. B; Sharma. R. R; Grover. $M$ and Sachdev. A. (2008). Mango explant browning: Effect of ontogenic age, mycorrhization and pre-treatments. Scientia horticulturae, 118(2), 132-138.

Laxmi. D. V; Sharma. H. C; Kirti. P. B and Mohan. M. L (1999). Somatic embryogenesis in mango (Mangifera indica L.) cv. Amrapali. Current Science, 1355-1358.

Litz RE and Lavi U. (1997). Biotechnology. In The mango: Botany, production and uses. Edited by Litz RE (CAB International, UK). 401- 423.

Litz, R. E and Gómez-Lim, M. A. (2005) Mangifera indica Mango. General Editor: Gabrielle J. Persley, The Doyle Foundation, Glasgow, Scotland., 40. Chicago

Litz. R. E and Yurgalevitch. C (1997). Effects of 1aminocyclopropane-1-carboxylic acid, aminoethoxyvinylglycine, methylglyoxal bis(guanylhydrazone) and dicyclohexylammonium sulfate on induction of embryogenic competence of mango nucellar explants. Plant cell, tissue and organ culture, 51(3), 171-176

Litz. R.E; M.A. Go'mez-Lim. and U. Lavi (2009) Biotechnology, p. 641-669. In: Litz, R.E. (ed.). The mango: Botany, production and uses. $\mathrm{CAB}$ International, Wallingford, UK

Nower A.A. (2013). In vitro production of somatic embryos from nucellus of mango (Mangifera indica L.). Life Sci J;10 (2):1164-1174.

Ochoa, E. D. C. M., Andrade-Rodríguez, M., Rodríguez, M. R., \& Monter, A. V. (2012). Identification of zygotic and nucellar seedlings in polyembryonic mango cultivars. Pesquisa Agropecuária Brasileira, 47(11), 1629-1636.

Pérez-Hernández, J. B and Grajal-Martín, M. J. (2011). In vitro culture of immature zygotic mango embryos and plantlet development. HortScience, 46(11), 1528-1532.

Sahijram. L; Bollamma. K.T; Naren. A;Soneji. J.R; Dinesh. M.R and Halesh. G.K (2005). In vitro embryo rescue in mango (Mangifera indica L.) breeding. Indian J Hortic 2005;62(3):235-7

Sawke .D.P; Ramtake. J.R and Deshmukh .M.T (1990). Irrigation and mulching studies in mango. International Symp. Natural Resources
Management for Sustainable Agriculture, 6-10 February, New Delhi;. p. 101

Shaban A.E, (2010): Comparative study on some polyembryonic mango rootstocks. AmericanEurasian Journal of Agricultural \& Environmental Sciences. 7 (5): 527-534 .

Smith. M. W; Bright. J. D; Hoult. M. D; Renfree. R. A; Maddern. T and Coombes. N (2008). Field evaluation of 64 rootstocks for growth and yield of 'Kensington Pride'mango. Hortscience, 43(6), 1720-1725

Stern. R. D, (1991): Review of 'CoStat- Statutical Software' Experimental Agriculture, 27, pp 8787.

Sulekha. G.R and Rajmohan. K (2004). Relative response of varieties and explants in the induction of somatic embryogenesis in mango (Mangifera indica L.). South Indian Hortic;52(1-6):5-12.

Xiao. J.N; Huang. X.L; Wu. Y.J; Li. X.J; Zhou. M.D and Engelmann. F (2004). Direct somatic embryogenesis induced from cotyledons of mango immature zygotic embryos, In Vitro Cell Dep. Biol. Plant. 40: 196-199. 